\title{
Multidisciplinary Curriculum to Teaching English Language in Sudanese Institutions (A Case Study)
}

\author{
Ishraga Bashir Mohammed Elhassan \\ English Department, Faculty of Arts, Alneelain University, Khartoum, Sudan
}

\begin{abstract}
Teachers in Sudan usually teach one subject in isolation, in other words they use the disciplinary approach. Stake holders recently are questioning the efficiency of the use of more than one discipline. It appears that clarification of a problem or discussing topics needs to relate different aspects together and that by melting various disciplines in one pawl to enable students to think critically and to have the ability to use the proper analogy and analysis of a concepts of their universe or the content under study. Teaching English language needs to integrate knowledge and contents. Designing a curriculum or a programme that help bringing different disciplines homogeneously to better educate students .It requires syllabus designers to design a program that incorporates the appropriate aspects of history, religion, politics business, communication, and other sciences that meet the objectives of the content being taught. This study builds a rationale for the combining different disciplines of the curriculum to be taught in Sudanese Institutions. Finally, this paper discusses small scale of a project that has melt more than one aspects of different contents, subjects and concepts and it has been implemented through problem solving method.
\end{abstract}

Index Terms - rationale, subject, interdisciplinary, multidisciplinary, integration, curriculum, language

\section{INTRODUCTION}

Language policy and language planning in the Sudan passed through four distinct stages: In the colonial times there was a clear-cut language policy: Arabic was for elementary education. English was for secondary education and college level. English was taught very economically, for the small groups that are to take the junior posts in the public service. At College level special English was to be taught for the prospective careers of the graduates. Towards independence some recognition was given to Arabic as a medium of instruction. After Independence there was no clear language policy. Matters were left to chance. After the conclusion of the Comprehensive Peace Agreement (CPA) between Sudan and South Sudan, the outline of language policy and language planning were drawn but they are yet to take shape and dimensions. There has been a general consensus of opinion often voiced by educationist and those concerned about the status of English language in the Sudan. All the parties who are concerned with the issue seem to unanimously agree that there has been a steady and continuous deterioration in the standards of English language amongst the students at all levels of education. This agreement has turned into an axiom that all people take for granted and over the years it has led to the development of uncompromising attitudes amongst all of the stakeholders. All these queries have to be taken on board if we are really keen to get into the depth of the problem. The introduction of the multidisciplinary approach to teaching and the learning of the English language is intended to satisfy the demand for a broad education that will meet the needs of modern Sudan of knowledge. Institutions are doing their very best to prepare their students for the job market.

\section{OBJeCtIVES OF THIS PAPER}

The objectives of this paper are:

1. To investigate the impact of the application of multidisciplinary or integrated approaches to English language teaching in Sudan.

2. To conduct a needs analysis the use of the multidisciplinary instruction to the teaching of language at the Sudanese institutions.

3. To present a small scale of a multidisciplinary project done by the national committee of curricula reforms and development.

\section{Definitions of The Key Terms}

This paper deals with two important approaches. The first one is what educationists call subject matter approach. The second one is the key term of this study, the multidisciplinary, or the integrated approach to teaching and learning. The simple descriptions of the terms are given below

- The subject matter approach is a teacher-centered approach where students are more passive participants in the learning process.

- A multi-disciplinary course involves different subjects of study in one activity.( Cambridge dictionary). 


\section{The SubJECT APPROACH}

The Subject approach in this paper means the teaching and the learning of language in a traditional way, which also means breaking the language into discrete components and taught them separately. Disciplinary approach also considers English language as subject and should be separately taught apart from other school subjects. English language in Sudan for decade is taught as a different subject from Psychology, Philosophy, and History and so on. In this way, each subject has a well defined boundary from which there is no connection to the other. The subject approach is the dominant approach in the Sudanese institutions.

\section{MultidiscipLinARY APPROACH}

Multidisciplinary approach to language teaching is an old/new approach. It came into the field of education and other fields, around 1920s, and it has once again gained attention in the United States as an alternative, or as an extension, to a separate subject curriculum (Akins \& Akerson, 2002; Goodlad, 2000; Perkins, 1991). "Teachers who emphasize a multidisciplinary approach usually keep the content of each subject intact, but they unite disciplines by organizing the curriculum around complex concepts, questions, themes, problems, or projects to capitalize on connections" (Akins \& Akerson; Mansilla, iller, \& Gardner, 2000; Ross \& Frey, 2002) cited in Janet C. Richards and Kim T. Shea University of South Florida, Tampa, Florida. Multidisciplinary in this paper means the comprehension of an issue, problem or concepts through various related or discrete subjects or disciplines. Natural language acquisition occurs in context; natural language is never learned divorced from meaning; and multidiscipline instruction provides a context for meaningful communication to occur (Met, 1991 cited in Bashoum); as well as combining content with knowledge second language acquisition increases with the involvement of more than two disciplines, because students learn language best when there is an emphasis on relevant, meaningful content rather than on the language itself.

\section{AdVANTAGES OF A MULTIDISCIPLINARY APPROACH}

There are many advantages in integrating more than one disciplines focusing on one problem, i.e. a multidisciplinary approach. Students are able to see and make connections, are required to make linkages among several subjects and disciplines. Students are enabled to explore the interrelationships between fields of knowledge. Students have a more unified sense of content and process. (Deborah, adeyemi 1998)

\section{RATIONALE FOR USE OF MULTIDISCIPLINARY APPROACH IN SUDANESE INSTITUTIONS}

The pace of changing the course books, methods of teaching and approaches are very slow. This means that too many 'lost generations' suffered through learning English by using out-of-date materials, Language is a living body. It changes rapidly. English language is especially particular in this regard. It changes round the clock. Do we teach our learners English or the History of English? For decades we use the same token, theories and principles of language and language learning. We should change so as to keep up with the advances in the field. Don't we need to keep pace with the swift change in this area? Periods that last for a decade, a decade and a half, or two decades in the ages of language courses are extremely long and they will inevitably create more problems than they can solve. One strong cause of the unacceptable situation of English language in the Sudan is the slow pace of change of material and ways of teaching. We cannot just go on pretending that we do not see. The rationale also behind using multidisciplinary approach Rather than limit the learning to one subject, is that, it highlights the connection between traditional content -- such as language arts, science, math, and history. Interdisciplinary teaching increases students learning abilities. It helps them to develop better problem solving skills and knowledge. The interdisciplinary approach teaches students how to think critically when faced with difficult issues. It also Helps Students uncover Preconceptions, helps students overcome the tendency to support their preconceived notions. Teachers through the multidisciplinary approach can introduce students to subject content from different perspectives. It also challenges their existing notions and allows students to look at where they came from. Once the student has set their pre-existing notions aside, they allow themselves to adopt a range of methods that promote learning. Research shows that multidisciplinary teaching increases motivation for learning. It also increases the level of active engagement. Those who take part in multidisciplinary learning become more involved in the process and recognize the value of what they have learned. When compared to learning methods in isolation, students participating in multidisciplinary learning understand new information better. Cognitive skills can be developed when using multidisciplinary approach and the students can carry out complex tasks. Students develop both procedural and declarative knowledge, which is needed to solve complex problems. It enhances students' knowledge formation capacity, so they can engage in discussion of complex. Greater learning occurs when teachers expose a range of skills and meaningful insight about the educational process to students. Teachers using the multidisciplinary approach encourage students to examine the disciplines that focus on social interaction when studying problems. As a result, multidisciplinary learning advances students understanding of how to learn by combining ideas from multiple disciplines together. (Jackie Rowson 20013). In Sudan we lack the skillful Economists, journalist, politicians, engineers... who master the language as well as their specializations; it is a fact that English is the language of progress and development .It is widely accepted that majority of new knowledge is created by developed countries in which 
English has enjoyed a special status. It is also recognized that developing countries enjoy efficiency gains if they adopt the knowledge created in developed country.

There are many justifications offered by researchers for the Use of multidisciplinary approach:

- an increase in interest in learning;

- Learning will be more effective, focused and purposeful;

- Learners will smoothly transfer what they have learned to all of the other fields of their lives; this should render them more useful members of their respective.

\section{English LANGUAGE TRAining IN THE CONTEXT OF MultidisciplinARY APPROACH}

The efficacy of an educational environment is principally determined by the approach educator's use, and the learning methods supported. It is obvious that educators in Sudan have to re-examine and update academic programs and language curricula introducing changes in the content and scope of the different subjects in the curriculum. Multidisciplinary academic programs represent the convergence of various disciplines in the language syllabus. Multidisciplinary programs are characterized by integration of topics; general subjects humanities, social sciences, management, are incorporated with professional language subjects. Since Sudanese learners have diverse ethnic, cultural and linguistic backgrounds, it is vital that they have the language skills and meaningful communicative competence necessary to understand and converse with people in and out Sudan, to obtain the required information, to make further research in the given area, and to provide mobility across world. It is precisely this fact that explains the barest necessity of foreign language integration into the curriculum, together with multidisciplinary skills. In this context, increasing coordination of foreign language training with the objectives and outcomes of the other disciplines and program is a necessity. Grounding of students in a foreign language must be synchronized with studying other subjects. The multidisciplinary approach can serve as a common and flexible platform for teaching various subjects including English for Specific Purposes (ESP), or English for Science and Technology (EST) as a form of ESP. For practical realization of the multidisciplinary approach, both traditional methods and new strategies can be applied and they must be based on the analysis of our graduates' goals. Some experts draw attention to a few innovative educational strategies that are employed to enhance language education: cooperative (active) learning, i.e. engaging students in doing and thinking instead of passive listening, wide use of information and communication technologies, project-based learning, etc. We may also combine universal educational strategies with some popular approaches, methods, techniques and models, which are widely used for the practice of the English language teaching. We need such approaches and methods, which will be focused on using particular language forms in a variety of contexts and for a diversity of purposes.

\section{LITERATURE REVIEW}

Research in the field of the use of the multidisciplinary approach vary in answering the questions of why, how, when and to which level should be used. Most of educationists in Sudan have supported the idea of using the multidisciplinary approach to small groups of learners and in a limited way. However, few of them have provided good and convincing reasons why. Some other researchers nationally and internationally argued that the integration of materials in other words the use of the multidisciplinary approach would help modernize or improve education. Professionals in the field of education view that it is there are good reasons to implement the multidisciplinary.. General topics which have been discuss are: theories of advanced learning and thinking, situated learning (context), transfer of learned knowledge, the nature of problems to be solved, and working in cooperative teams. (Robert C. Wicklein and John W. Schell1995).

\section{LEARNING AND CRITICAL THINKING}

Thinking critically believed to be occurring when students face a problem or a challenge, and that happens when integrating various, disciplines, domains of knowledge and experience in homogeneous way. The process of articulating a learning program that yield to learning how to think critically and in order to construct knowledge base, forces learners to reflect on what they are studying in new and meaningful ways. It is a mere fact that students learn through an integrated program have better chance to make connections between the logic of the different disciplines, and what is important in life. Multidisciplinary education provides a rich context for the manifestation of critical thinking. In integrated programs, students are challenged to determine the basis of arguments and analyze truth claims across disciplines (Kelder, 1992 cited in Lana Ivanitskaya, Deborah Clark, George Montgomery, annd Ronald Primeau ).

\section{TRAnSFER OF KNOWLEDGE}

Students, as the result of learning, automatically and directly transfer what they have learned from one discipline to another and to workplace and life settings. Many of the important concepts, strategies, and skills taught in the language arts, they transfer readily to other content areas. Many concepts may be found in discreet disciplines for example Science and Arts. Strategies for learning and assessing a written or an oral text can be directed to reading material in any 
content area. Cause-and-effect relationships exist in Arts science, and social studies. Interdisciplinary/cross-curricular teaching supports and promotes this transfer. Critical thinking can be applied in any discipline.

\section{The MulTidisciplinARY PROJECT}

\section{A. The Project Underwent through Four Stages These Are:}

\section{B. Stage One. Setting the Main Plan and the Sub Plans:}

Multidisciplinary approach is like any approach needs to set a well-constructed action plan. Where there are sub plans for the teachers that are involve in the project. The main plan consists of subjects, specific information and knowledge, we refer to it as" subjects needed contents" in other words it describes the context. The word context in this project means the overall teaching and learning environment, program, and curriculum. The sub plans are lessons plans and also we call them scenarios. They describe the stages of each lesson, the role of each teacher, the pace, the time, the activities, and the role of the students. We have started be combining the Sudanese culture and English language. Other combinations can be math, music, language arts and technology. Teachers are engaged in what we call it rehearsal stage. In this stage teachers lean how to cooperate, and teach together. One of the efficient training program is that we ask teacher to shadow professors performing multidisciplinary approach. Teachers of English are asked to attend lectures in other disciplines in other words we ask teachers to engage collecting information about the different disciplines.

\section{Stage Two. Choosing the Subjects and Institution}

Subjects: The multidisciplinary program is set at the Ahfad University for first year of pre-sessional programme. The course is offered by the University to provide all incoming students with the foundational knowledge necessary to proceed in their general and specific areas of study. The Foundation Program aims to bridge the gap between secondary school and university education. The English Program is designed to build skills in reading, writing, listening, speaking, vocabulary, grammar, critical thinking, and self-learning.

Instructors: The instructors who participated were:four full time lecturers and twenty three partime lecturers.

\section{Stage Three: The Process of Teaching and Learning}

The students were 100 divided into five groups. The course started on the $6^{\text {th }}$ of October 2010.The students worked 4 contact hours a day for 3 days a week. They studied for ten weeks then they took a proficiency test to be promoted to level two. With this instructional design, students received both English and Sudanese studies and culture credit. Teacher-led discussions were followed with video presentations, student learning exercises, and experiments relating to the major components curriculum. Curriculum is divided into steps and parts each taught by the teacher who master both the process and the knowledge of the content. Teachers supplement their plans by materials chosen according to the students interest and level. This motivates and encourages teachers to participate in the designing of the syllabus. As for students are required to write reports do assignment then presented to the class.

\section{E. Stage Four: The Proficiency Test}

Students were took a final proficiency test. The test was taken from the students' material provided by the project planners and the teachers. The following table shows the students results which show that the overall situation is good despite few problems.

\begin{tabular}{|l|l|l|l|l|l|l|l|}
\hline $\begin{array}{l}\text { Numbers of } \\
\text { Students }\end{array}$ & $\begin{array}{l}\text { Absent } \\
\text { Students }\end{array}$ & Absent \% & $\begin{array}{l}\text { Attended } \\
\text { Students }\end{array}$ & Passed & Passed \% & Failed & Failed \% \\
\hline 100 & 11 & 10.6 & 89 & 71 & 80 & 18 & 20 \\
\hline
\end{tabular}

\section{F. Problems}

The problems can be summarized as follow: 1. Class room conflict and availability of the rooms.2.there are problems associated with the part timers, one of the major drawbacks is that they are less commented and the turnover rate among them is significantly higher than the rate of the full timers. About ten percent of the par timers did not follow the proposed plan. 3. Insufficient time. 4. No Internet access, computers and projectors.

\section{G. Findings}

We can safely say that multidisciplinary approach to teach English Language have made a positive impact in both Teachers and students. We found that teachers are open to change and are willing to challenge themselves and their students to enhance students motivation, self-efficacy, self-steam that lead to effective learning, this project works as a trigger for more improvements in a country like Sudan that has limited resources to train teachers and to educate students a quality education that can be transferred to work place and life settings at large. Multidisciplinary approach can help teachers to learn from each other regarding the teaching strategies and knowledge

\section{CONCLUSION}


Multidisciplinary found to be very efficient in Sudanese institutions because it increases cooperative teaching as well as learning. Knowledge can be transferred to real life settings and that by crossing boundaries among the disciplines. Students are able to develop their learning self-efficacy. It develops the tendency of team work in addressing and solving a problem with input from a large variety of views. Teachers enhance their knowledge of various disciplines.

\section{REFERENCES}

[1] Akins, A., \& Akerson, V. L. (2002). Connecting science, social studies, and language arts: An interdisciplinary approach. Educational Action Research, 10,479-497.

[2] Cambridge Advanced Learner's Dictionary \& Thesaurus ( Cambridge University Press.

[3] Collins English Dictionary - Complete and Unabridged @) HarperCollins Publishers 1991, 1994, 1998, $2000,2003$.

[4] Deborah adeninhun adeyemi, justification of a multidisciplinary approach to teaching language in Botswana junior secondary schools, Journal of language technology \& entrepreneurship in Africa Vol2.No.1.2010, ISSN19998-1279.

[5] Jackie http://www.ehow.com/info_8786831_benefits-interdisciplinary-teaching.html. 22/12/2013 8:00 PM.

[6] Jackie Rowson. (2013). at http://www.ehow.com/info_8786831_benefits-interdisciplinary-teaching.html\#ixzz2nOa9j2Rq 22/12/2013 8:00 PM.

[7] Met, M. (1991). Learning language through content: Learning content through language. Foreign Language Annals. cited in Bashoum English Language Education in the Sudan: Towards a Developmental Model of Integrated Solutions (Conference Paper).

[8] P1: GRA/GGT Lana Ivanitskaya, Deborah Clark, George Montgomery, and Ronald Primeau Innovative Higher Education Ph153-ihie-453019 November 13, 2002 14:10 Style file version March 31, 1999 Innovative Higher Education, Vol. 27, No. 2, Winter 2002 (Cœ2002).

[9] Proceedings of the Conference held at the University of Khartoum, January 1966.

[10] Robert C.Wicklein john W.Schell, (1995). Case Studies of Multidisciplinary approaches to integreating Mathematics, Science and Technology Education Journal of Technology Education, volume 6, number2 spring.

[11] The American Heritage Dictionary of the English Language, Fourth Edition copyright (C2000 by Houghton Mifflin Company. Updated in 2009. Published by Houghton Mifflin Company.

[12] The Comprehensive Peace agreement between the Government of the Republic of The Sudan and The Sudan People's Liberation Movement/Sudan People's Liberation army.

[13] The Interim National Constitution of the Republic of the Sudan, 2005.

[14] The Qualitative Report Volume 11 Number 1 March 2006 1-19 http://www.nova.edu/ssss/QR/QR11-1/richardsshea.pdf. 22/12/2013 8:00 PM.

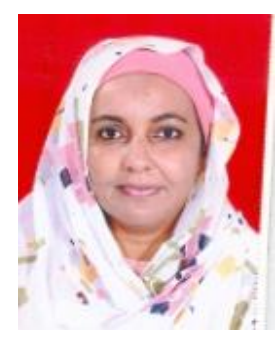

Ishraga Bashir Mohammed Elhassan graduated from Khartoum University with B.A in French Language, then postgraduate diploma in French from France, followed by postgraduate and M.A. in English language from Khartoum University and finally Ph.D. from Khartoum University. She did training courses in Teaching English as second language from Garnet Education and Ahfad University. She started her carrier at Sudan University as a lecturer. Now she is working as Associate Professor at Alnilain University. She is supervising M.A. and $\mathrm{PhD}$. students. She consults regularly with colleagues from a variety of universities to help for better English language skills for university students. Prior to her current position, she is the head of research committee and lecturing M.A courses in other three Sudanese universities. And she is The president of TESOL Sudan. 